\title{
DESENVOLVENDO NARRATIVAS ANIMADAS PARA A EDUCAÇÃO: a jornada de um designer animador
}

\author{
Gabriel Filipe Santiago Cruz \\ PUC-Rio \\ prof.gabrielcruz@gmail.com \\ Luiza Novaes \\ PUC-Rio \\ lnovaes@puc-rio.br \\ Rita Maria de Souza Couto \\ PUC-Rio \\ ricouto@puc-rio.br
}

\begin{abstract}
Resumo: Com o objetivo de divulgar os resultados obtidos na pesquisa de campo realizada na dissertação Desenvolvendo narrativas animadas para a educação, o presente estudo propõe uma metodologia interdisciplinar para a criação de narrativa animada, que possa ser utilizada tanto como material didático em sala de aula, como também para entretenimento. Muitos são os desafios para que um novo material seja criado a partir de uma metodologia colaborativa recente, sem se caracterizar como apenas uma nova roupagem para antigos modelos. Fundamentado em conceitos como aprendizagem significativa e educação como introdução a realidade total, este artigo apresenta um estudo de caso, de produção interdisciplinar de uma narrativa animada para ser utilizada por professores em sala de aula.
\end{abstract}

Palavras-chave: Animação educativa, narrativa animada, jornada do herói

\begin{abstract}
The objective of this study is to publish the achieved results of a research developed at the Master's Dissertation "Developing animated narratives in education". The present study purposes an interdisciplinar methodology for the creation of animated narratives that can be used both for didatic material in classrooms and entertainment as well. There are many challenges in developing didatic material out of a fresh colaborative methodology, instead being just a new facade for old models. This essay presents a case study, based on concepts such as meaningful learning and education as introduction to total reality, of an interdisciplinary production of an animated narrative to be used by teachers in classrooms.
\end{abstract}

Keywords: educational animation, animated narrative, hero's journey 


\section{INTRODUÇÃO}

A linguagem audiovisual tem sido vista como um forte instrumento de auxílio no processo de aprendizagem. É cada vez mais comum aos professores a utilização de filmes, animações e jogos eletrônicos nas escolas, servindo como material de reforço para ajudar a fixar os conceitos trabalhados em sala de aula.

No entanto, o uso dessas linguagens e a metodologia para a elaboração de materiais didáticos utilizando mídias emergentes ainda representam um grande desafio para o professor. Acostumado há anos com a sala de aula - o giz, o quadro negro, o livro-texto e com as pesquisas de seus respectivos laboratórios - ou até mesmo por ter se adaptado aos poucos à nova era da informação o professor acaba encontrando certa dificuldade para incorporar esses novos recursos a suas atividades.

Para auxiliar o professor a enfrentar esse desafio, instituições especializadas em Educação contratam times multidisciplinares de profissionais para levar adiante seus projetos. Dentre esses profissionais, os da área de Design Gráfico têm sido bastante solicitados a auxiliar no processo de produção de materiais didáticos para o meio digital.

No entanto, na maior parte das vezes, no processo de produção de aulas com mídias digitais, o designer é visto como um profissional que tem uma pequena participação na execução e elaboração dos chamados "objetos de aprendizagem".

Salvo algumas exceções, o material animado costuma ser visto como uma espécie de "lousa dinâmica" com explicações técnicas do conteúdo a ser abordado pelo professor.

Diante desse quadro, apresentam-se algumas questões para reflexão: Como a metodologia de projeto pode ajudar o professor a elaborar um material de fato atrativo para o aluno? Como o designer pode se tornar um parceiro real do professor neste processo? Como a linguagem da animação pode ser melhor explorada neste processo?

Com o crescimento do mercado de animação no Brasil, tem sido feita uma reflexão sobre a formação desses profissionais. Até pouco tempo atrás, boa parte dos animadores iniciava sua carreira de forma autodidata. Buscando uma formação mais sólida, as escolas de Design têm tomado algumas das mais interessantes iniciativas como a primeira especialização em Cinema de Animação da PUC-Rio; e o curso de graduação tecnológica em Design Gráfico com ênfase em llustração e Animação Digital da UVA. Com isso, o Design, além de ser uma atividade de caráter interdisciplinar, acaba adquirindo o papel de responsável por um diálogo em potencial com a área de animação no país.

Além do caráter interdisciplinar do Design como fundamento deste trabalho, também o é a ideia de David Ausubel sobre aprendizagem significativa onde afirma que para que um novo conteúdo tenha algum significado para o aluno é necessário: um material instrucional bem elaborado com estrutura lógica; que esteja ligado a um conhecimento prévio do aluno e que se encontre de alguma forma bem disposto a aprender o novo conteúdo.

É neste cenário que a linguagem da animação, cujo roteiro é apresentado de forma atrativa para o aluno, pode servir como proposta de apresentação de um novo conteúdo do currículo escolar. E daí que se inicia a descrição dos passos dados nesse trabalho. 
Inicialmente, buscou-se ambientes escolares para estabelecer uma parceria de trabalho com professores para elaborar uma narrativa animada, que pudesse ser utilizada em sala de aula.

Com o roteiro em mãos, foi elaborado um animatic ${ }^{1}$ do curta e testado o roteiro em uma escola com os alunos; com os resultados, montou-se uma pequena equipe para produzir o curta.

Por fim, foram feitas algumas considerações sobre os resultados obtidos neste estudo de caso.

\section{DESENVOLVIMENTO}

Nesta parte do trabalho, foi relatado o estudo de caso de metodologia para a criação de uma narrativa animada, visando o seu uso por professores em sala de aula. A divisão das etapas deste texto é inspirada na Jornada do Herói, conceito originário da Psicologia Junguiana e dos estudos míticos de Campbell, e na Jornada do Escritor, de Christopher Vogler. Por isso, os títulos de cada subcapítulo remetem a um passo da "Jornada do Escritor", acrescido de um complemento, relacionado ao contexto específico do trabalho realizado.

\subsection{Mundo comum: o trabalho com animações educativas}

Nas experiências como animador, um dos autores encontrou dois padrões de equipes de criação de narrativas animadas: ou os roteiros eram produzidos por um professor de uma determinada área de conhecimento com o designer (animador, comunicador visual) sendo visto como um executor, e o produto final considerado um "material didático com movimento" ou a figura do professor era vista como apenas um consultor para um filme, com objetivos de entreter puramente, sendo o conceito cientifico apenas uma forma de tornar a narrativa mais verossímil.

\subsection{O chamado a aventura: a busca por professores}

$\mathrm{Na}$ proposta de criar uma narrativa animada com fins educacionais e de entretenimento ao mesmo tempo, apostou-se na criação de uma equipe interdisciplinar onde professores e animadores interagissem no projeto. Neste processo, as barreiras das respectivas áreas tornam-se, na verdade, um complemento para um processo colaborativo.

O passo inicial foi a busca por professores que pudessem se interessar em participar deste projeto. As conversas iniciais com alguns profissionais conhecidos mostrou que todos tinham interesse em conseguir ensinar algum tópico específico através da animação. No entanto, pode-se notar que todos ainda estavam muito arraigados ao velho problema do livro didático, sem abertura para novas propostas.

\subsection{Recusa ao chamado: desânimo e retrocesso}

A criação de uma equipe de professores para criar narrativas fantásticas com seus respectivos conteúdos mostrou-se um problema em função da dificuldade de reuni-los. Mostrou-se mais complicado ainda juntar professores de diferentes áreas

\footnotetext{
${ }^{1}$ Etapa de produção de um filme de animação onde as cenas são exibidas com pouco movimento ou movimentos grotescos, diretamente tirado do storyboard. Nesta etapa ainda é possível fazer modificações consideráveis na história sem que haja risco de comprometimento do cronograma da produção.
} 
para produzir algo neste sentido. Somando-se a isso tudo, existia também a necessidade de participação de roteiristas e designers animadores, para que o processo se completasse de forma ideal.

A primeira solução aventada foi retroceder a um dos métodos de produção apresentados no item 2.1 deste trabalho e produzir a narrativa animada apenas com uma equipe de animadores, tendo os professores como consultores de conteúdo. Esta seria uma situação confortável, mas comum. Não víamos nessa solução simples o melhor caminho a ser seguido.

\subsection{Um novo caminho e o início da jornada}

Este foi um ponto chave da pesquisa em que foi preciso recorrer aos orientadores de projeto. A nova proposta surgiu a partir da busca de professores que não apenas achassem interessante a ideia da animação, mas que realmente se empolgassem com ela. Reiniciou-se então a jornada através da busca de uma parceria para o projeto.

\subsection{Travessia do primeiro limiar: o desafio de estabelecer a parceria}

Inicialmente uma escola recebeu de braços abertos a proposta, se interessando muito pela questão do uso da animação. Porém, durante a explicação da mesma, ao falar da necessidade de ter pelo menos um professor da escola na equipe, a barreira burocrática se apresentou. Não havia problema em usar o espaço da escola para reuniões, mas eles não tinham condições de disponibilizar um professor para participar da elaboração do roteiro, mesmo sendo o professor voluntário, pois a escola temia a possibilidade deste exigir o pagamento de hora-extra.

Mudando a estratégia para realizar o trabalho, buscou-se identificar pessoas conhecidas que pudessem ter interesse no trabalho. A valiosa dica dada no encontro com os orientadores do projeto retumbou na cabeça: "Procurar alguém sedento para quem se pudesse oferecer água." As pessoas foram identificadas em um grupo de jogadores de RPG ${ }^{2}$ onde havia integrantes que se tornaram professores em alguma área de conhecimento.

Uma das razões de contatar antigos jogadores de RPG é a facilidade e a capacidade que esses jogadores têm para desenvolver narrativas. No RPG a dinâmica do jogo envolve três ou mais pessoas, onde uma delas, geralmente chamada de "mestre", desenvolve uma narrativa e as outras interpretam, cada uma, uma personagem na aventura sugerida.

Em conversa com o Professor de Geografia Luiz Fernando Cardoso ficou patente a empolgação que precisávamos para montar a equipe. Com a ajuda dele, conseguimos integrar à equipe a Profa. Eline Berty, de Química, tornando possível a criação de um trabalho interdisciplinar com duas áreas do conhecimento aparentemente bem distintas.

\subsection{Testes, aliados e inimigos: o desenvolvimento de uma narrativa}

Após conseguir o apoio de dois professores para o projeto, restava buscar o grupo dos profissionais que já trabalhavam em animação.

\footnotetext{
${ }^{2}$ RPG (Role Playing Game) - jogo no qual o jogador assume papéis de diversos personagens em um ambiente ficcional, assumindo a responsabilidade de atuação através de uma narrativa.
} 
Juntamente com os professores, foram chamados também para compor esta equipe de roteiro dois animadores: Marcos Cesar da Silva Filho, artista 3D da Full Frame Filmes; e Suzani Figueira, animadora e estudante de Design da PUC-Rio. A equipe formada tinha como primeira tarefa elaborar, em três reuniões, o roteiro do projeto.

O primeiro passo foi fazer um levantamento inicial de dados com os professores. Que conteúdos, em suas respectivas áreas, acreditavam que os alunos tinham maior dificuldade de aprender? Era possível juntar esses conteúdos em uma única situação? Existiam outros conteúdos, de outras disciplinas, que podiam ser também incorporados para serem tratados e trabalhados?

Inicialmente pediu-se aos professores que citassem tópicos do currículo escolar onde eles identificavam dificuldade de aprendizado por parte dos alunos. Cada tópico citado era anotado: ligações químicas, química orgânica, tabela periódica, cartografia, formação dos continentes, geologia e reações químicas foram alguns dos tópicos citados. Logo em seguida foram separados alguns desses tópicos em categorias para facilitar o processo de criação.

Com os tópicos citados e selecionados, chegou a hora de definir o mote da narrativa animada. Surrel (2009) cita como um dos exercícios iniciais para criação de narrativas animadas a elaboração de perguntas de situações diversas, sempre começando com "E se...". E assim começamos, sem restrições a elaborar diversas situações curiosas como "E se um cientista maluco resolvesse dar a volta ao mundo tentando descobrir novos elementos?" ou "E se um pirata fizesse um mapa do tesouro com tintas químicas e quisesse voltar ao X?"

E assim a reunião seguiu, aproveitando a liberdade que o universo da animação nos oferece, tornando qualquer coisa possível, até surgir a pergunta: " $E$ se dois átomos de oxigênio passassem milhares de anos tentando ficar juntos e fossem sempre atrapalhados por carbonos e hidrogênios?". E foi por aí que decidimos aprofundar, pois ao contrário das outras perguntas, ela logo nos fez levantar vários desmembramentos e ligações com muitos dos tópicos anotados anteriormente.

A pergunta gerou um braistorming ${ }^{3}$ diversificado, rico e amplo. Os dois átomos iriam viajar pelo planeta durante diversas eras geológicas para encontrar o tão esperado lugar onde viveriam tranquilos. Ao ficarem submersos e ligados, cada um a dois átomos de hidrogênio (formando uma molécula de água), seriam "sugados" por um estromatólito, e cuspidos de volta, interligados como uma molécula de oxigênio, da forma como tanto sonhavam. Mas, logo depois veriam outras moléculas sendo sugadas por um outro organismo e cuspidas de volta com um Carbono (dióxido de carbono). Estava aí sendo trabalhado o conceito respiração, fermentação e ligações químicas. Durante a viagem pelas eras geológicas, surgiriam mapas da Terra em diferentes fases, começando pela Pangéia e chegando até dos dias de hoje. Os mapas apareceriam em diversos ângulos diferentes, para aí ser trabalhado o conceito de cartografia. Em cada cenário, por exemplo, gelo e vulcões, haveria moléculas vibrando em diferentes velocidades, possibilitando trabalhar o conceito de temperatura. A cada nova ideia, uma chuva de possibilidades a serem trabalhadas em sala de aula surgia. $E$ o melhor de tudo, lá estavam conceitos de Química, Geografia, Biologia e Física. A

\footnotetext{
${ }^{3}$ Brainstorming: do inglês "tempestade de ideias" é uma técnica de atividade em grupo onde o objetivo é, através de sugestões informais e espontâneas de seus integrantes, chegar a uma proposta de produto a ser desenvolvido.
} 
história foi ficando naturalmente integrada. Foram mais três reuniões para se discutir a história, desenhar concept arts ${ }^{4}$ (figuras 1 e 2) das personagens, resumi-la e partir para a próxima etapa. E assim ficou a sinopse:

Dois átomos de oxigênio buscam desesperadamente, desde os primórdios da Terra, viver sozinhos e em paz com seus semelhantes. Para isso, eles irão, ao longo de várias eras geológicas, viajar pelo planeta em busca de um lugar onde possam enfim descansar livres dos carbochatos e hidrobaixinhos, que sempre vivem espreitando-os.
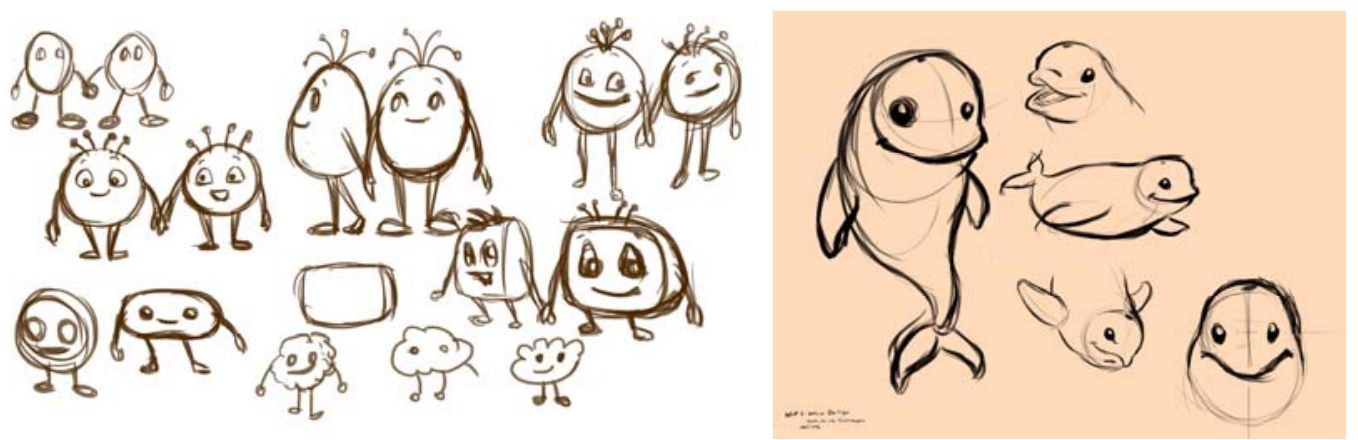

Figura 1 concept arts dos átomos de oxigênio para a produção (Suzani Figueira).

Figura 2 concept arts de uma beluga para a produção (Daniel Oliveira)

Fonte: Elaborado pelo autor, com base na pesquisa realizada

Durante a criação do roteiro, nasceu outra questão: quanto tempo deveria ter o curta? Voltamos então ao objetivo do projeto: se o principal conceito é que o professor use a animação em sala de aula como um material de apoio, ela deve desencadear uma discussão com os alunos sobre o assunto abordado. A animação não fechará as explicações em si. Logo, num tempo de aula de 50 minutos, ela deve ter uma duração que permita sua exibição, além de um tempo para refletir, dialogar e trabalhar os conceitos nela desenvolvidos. Assim, uma duração de 3 a 5 minutos se mostrava adequada.

O desafio, então, passou a ser elaborar uma história rápida, curta, mas rica em detalhes e com vários assuntos, para ser utilizada em sala de aula.

Com o roteiro pronto, finalizamos o storyboard e começamos a produzir o animatic $^{5}$ do curta (figuras 3 e 4). De posse do animatic, tinha chegado a hora de testar o filme. Em animação não podemos pensar em modificar um filme depois de todas as artes prontas - daí a necessidade de testes prévios para confirmar as decisões tomadas em relação a tempo, enquadramentos etc. Eliminar cinco segundos de uma animação pronta significa desperdiçar três ou quatro semanas de trabalho de um animador. Por essa razão, em geral toda edição de um filme de animação é feita no storyboard ou, em último caso, no animatic do filme.

\footnotetext{
${ }^{4}$ Concept art: forma de ilustração na qual o objetivo principal é representar/testar visualmente um design, ideia e/ou modo de ser, contextualização, que norteará a produção no desenvolvimento de filmes, videogames, ou revistas/livros antes da solução final adotada.

${ }^{5}$ Versão de arquivo de vídeo com animações ainda brutas e iniciais, mas já com as falas e o tempo corretos.
} 

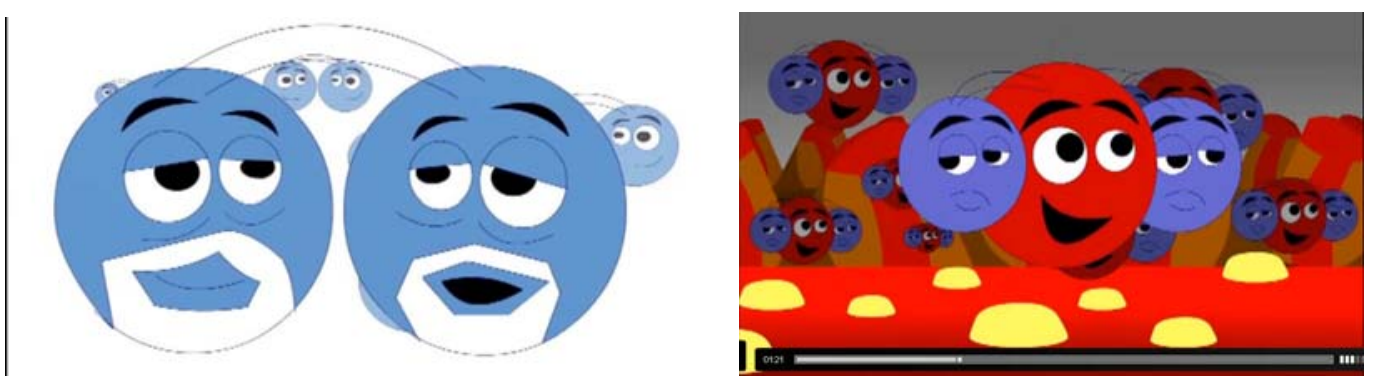

Figuras 3 e 4 - cenas do animatic da produção

Fonte: Elaborado pelo autor, com base na pesquisa realizada

Por essa razão, achei interessante nesta fase mostrar o filme a alguns estudantes do ensino médio, público-alvo definido para esta animação. Assim, poderíamos verificar se a narrativa em questão funcionava como objeto de entretenimento, e se também poderia ser utilizada como objeto a ser trabalhado em sala de aula, para a apreensão de conteúdo.

\subsection{Aproximação da Caverna Oculta: a busca de um local para testar o filme}

Não se mostrou interessante passar o filme para os alunos dos professores que trabalharam no roteiro, pois era preciso evitar qualquer tipo de influência que poderia ser gerada pelo vínculo entre aluno e professor. Depois de uma conversa com o professor Luiz Fernando, foi feita uma listagem de outras escolas para serem contatadas e finalmente obtivemos a aprovação do Colégio Nossa Senhora da Ressurreição. A coordenadora do ensino médio imediatamente agendou um encontro com os alunos na semana seguinte.

De acordo com nosso planejamento, foi pedido que fossem indicados seis alunos - três do primeiro ano do ensino médio e três do segundo ano - para participarem do teste. Solicitamos também que o perfil dos alunos indicados fosse variado, alguns com destaque nas notas e outros com dificuldade, mas que não fosse dito a equipe da pesquisa, até terminar o filme e conversar com os alunos, quem era quem na sala. Afinal de contas, não queríamos ser influenciados a achar que um aluno respondeu as perguntas feitas após a exibição do animatic mais por sua história de desempenho acadêmico do que pela qualidade e eficiência do animatic apresentado.

\subsection{Provação: o encontro com os alunos}

O encontro para a realização do teste aconteceu logo após o recreio, na biblioteca. Para deixar o clima menos formal possível, foi levado o animatic no tablet e discutido numa espécie de mesa redonda.

Para manter o clima interdisciplinar proposto no projeto, o Prof. Luiz Fernando também esteve presente. Ele poderia, com seu olhar de educador, identificar coisas que o olhar dos designers poderiam deixar passar batido. Ele não se identificou como professor para os alunos, para evitar que eles fossem influenciados por sua presença.

Aos estudantes, reunidos na biblioteca, foi explicado o objetivo da apresentação e qual a ajuda que queríamos deles. Os estudantes foram orientados a falar o que quisessem em relação ao curta. Eles ficaram empolgados ao ver que estavam participando do processo de produção e que iam ver um filme ainda em fase de criação. Para eles, a sensação de ter um certo poder de decisão sobre o direcionamento da produção os deixou mais empolgados para ajudar. 
O animatic foi exibido e a seguir foi entregue a cada aluno um pequeno questionário de múltipla escolha.

Seguem as perguntas e seus resultados (Figura 5)
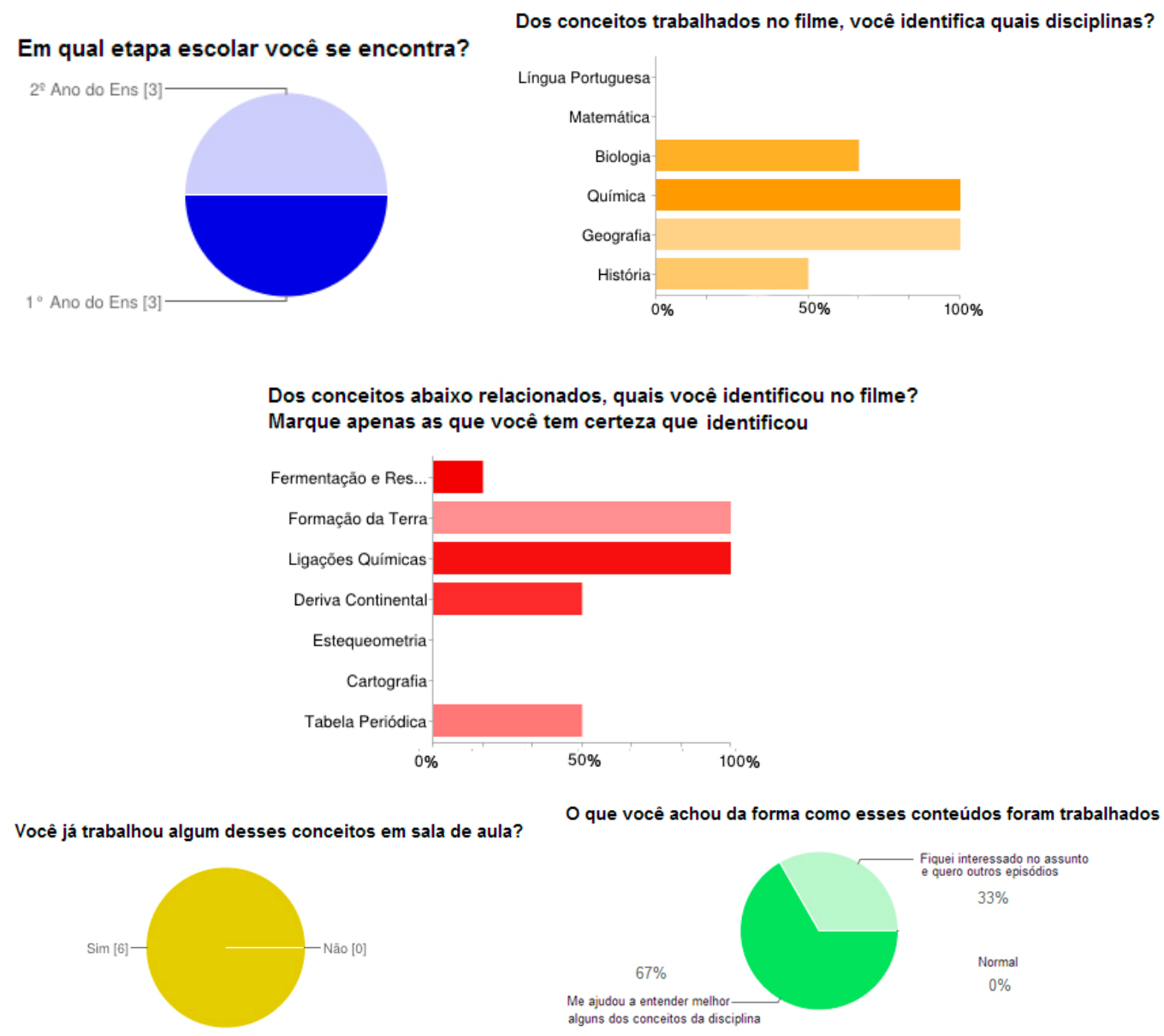

Figuras 5 - Resultados da pesquisa feita com os alunos

Fonte: Elaborado pelo autor, com base na pesquisa realizada

De acordo com os resultados, todos identificaram as disciplinas de Química e Geografia, que são de fato as que possuem maior destaque no roteiro; pouco mais da metade dos alunos identificou também Biologia e metade relacionou a viagem pelo tempo como História. Sobre os conceitos abordados, as ligações químicas e a formação da Terra foram notadas também por todos. A Deriva continental foi identificada por metade dos alunos, o que foi considerado um resultado bem interessante porque no animatic os mapas não estavam tão bem definidos e mesmo assim foi notado por alguns dos alunos que eles estavam diferentes e se separando em continentes. Por fim, o resultado final onde aproximadamente $1 / 3$ dos alunos afirmou passar a ter mais interesse no assunto. Os outros $2 / 3$ afirmaram que o conteúdo ajudou a entender melhor os conceitos elaborados na disciplina. Interessante notar que não houve indiferença em relação ao uso da Narrativa animada. Todos, de alguma forma, foram ajudados ou incentivados a entender melhor $o$ assunto.

\subsection{Recompensa: o resultado}

Todos responderam rapidamente ao questionário, mas acabaram travando na questão discursiva, que pedia para eles tecerem comentários que pudessem ajudar a 
melhorar o filme. Neste momento, decidimos abrir mão da questão discursiva e passar para a realização de uma entrevista semiestruturada com os alunos. Para buscar entender as impressões que os alunos tiveram sobre o filme que assistiram, foram preparadas algumas perguntas:

- O que acharam do curta?

- Gostariam de ter a narrativa animada como recurso didático?

- Identificaram a interdisciplinaridade entre os conteúdos?

- Teriam alguma sugestão de modificação na história?

Ao fazer a primeira pergunta, os alunos resolveram logo comentar sobre os tópicos do filme, alguns perguntaram se uma das cenas correspondia ao conteúdo $X$, como se quisessem que confirmássemos o que eles tinham entendido. Falaram que gostaram bastante, principalmente da abordagem da questão ambiental. Neste momento ficamos surpresos, pois nem a equipe tinha pensado na cena final, onde os oxigênios são soltos de dentro de um iceberg porque ele tinha derretido, como algo que levantasse a questão ambiental.

Logo em seguida, aproveitando a empolgação dos alunos, o Prof. Luiz Fernando resolveu perguntar o que eles achavam da possibilidade do curta ser usado por um professor em sala de aula. Todos concordaram que seria ótimo e que ajudaria os alunos a entender melhor alguns conceitos que são abstratos demais. Mas assumiram que era necessária a presença de um professor para ajudá-los a aprofundar melhor os conceitos trabalhados, o que também nos fez confirmar a hipótese de que, neste caso, a narrativa animada serviria como um recurso didático, um pretexto, mas não como um material com conteúdo fechado em si.

Ao perguntar sobre a identificação da interdisciplinaridade entre os conteúdos, veio outra surpresa. Para os alunos, verem uma situação onde tantos conteúdos aparecem ao mesmo tempo, os ajuda a guardar, entender e memorizar os conteúdos. Como disse uma das entrevistadas "Usando essas coisas, a gente passa a saber a matéria e assim não precisa de cursinho pré-vestibular".

Nesse momento, a entrevista foi um pouco mais além do que tínhamos planejado. Passamos a conversar sobre a função do Ensino Médio, já que tinha surgido essa provocação. Afinal, era legal ver o curta por causa do Vestibular ou para ter o conhecimento? Então os alunos concluíram que o ENEM era importante, mas levar o conhecimento do Ensino Médio para a vida era bem mais.

Logo retornamos ao curta e, depois de tantas trocas, pedimos as sugestões que tinham para a animação. Como acabamos dizendo aos alunos que não tínhamos percebido a questão ambiental, eles sugeriram então que trabalhássemos mais essa questão e que, de alguma forma, apresentássemos o derretimento do iceberg como consequência da ação humana. Deixaram bem claro que tinham sentido falta desse ponto no curta.

$\mathrm{Na}$ entrevista, todos os alunos foram igualmente participativos. Não foi possível distinguir quem eram os alunos com facilidade e os com dificuldade de aprendizado. Após o teste, ficou claro que o curta estava funcionando e que poderíamos dar prosseguimento à sua produção.

\subsection{Caminho de volta: mais descobertas e colaborações}

Finalizada a entrevista com os alunos, em conversa com a coordenadora do ensino médio, ela se mostrou surpresa pelo fato de não havermos distinguido os 
alunos com dificuldade dos com facilidade. De acordo com ela, dos seis alunos selecionados, dois tinham notas de destaque, dois notas regulares - acompanhavam a média mínima para passar, e outros dois tinham sérios problemas, sendo um repetente e o outro diagnosticado com traços de autismo.

Constatamos que produzir uma animação potencializa não só o trabalho dos alunos em relação ao conteúdo, como também a socialização entre eles. Os assuntos que surgiram durante a entrevista foram além dos conteúdos, passando pelo trabalho do docente, pela importância desta pesquisa da qual participaram, e por questões de como poderíamos ajudar os alunos a vivenciar um ensino médio voltado mais para a busca do conhecimento e menos para a busca unicamente de um bom resultado na prova do ENEM. Um ensino mais comprometido com a máxima "passar a saber para não precisar de pré-vestibular."

\subsection{Ressurreição: o aperfeiçoamento do roteiro, equipe revigorada.}

$\mathrm{O}$ encontro reanimou nosso trabalho. Após relatar o teste do animatic à pequena equipe formada para criar a história, foi refeito apenas o pequeno final dando uma valorizada na quantidade de carbonos, justamente para tratar do aquecimento global e da interferência do homem na natureza, assuntos sugerido pelos alunos. $E$ partimos para a produção do curta.

Renovados pelo resultado parcial do trabalho, não foi difícil conseguir mais pessoas para a produção do curta. A equipe ampliada trouxe novo gás para o projeto. Até uma nova técnica, pois o curta - que inicialmente seria desenvolvido com a técnica de animação 2D - passou a ser em 3D (figuras 6 e 7).
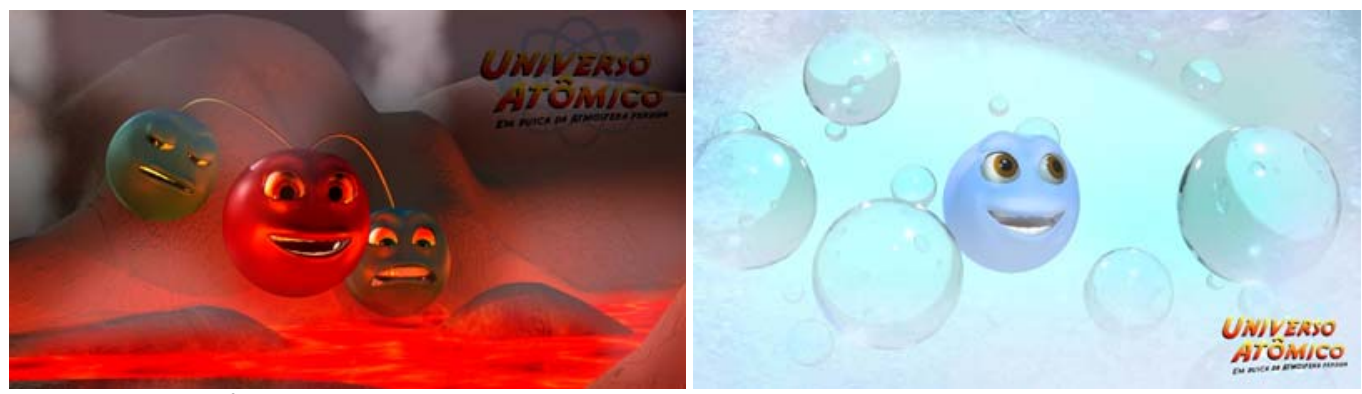

Figuras 6 e 7 - Átomos e cenários modelados em 3D (Leandro Meirelles)

Fonte: Elaborado pelo autor, com base na pesquisa realizada

Para agilizar o processo, passamos a nos comunicar por um grupo criado no Facebook e a usar uma planilha, com o planejamento e cronograma do projeto, no Google Docs. Desta forma, utilizando recursos que facilitam o trabalho remoto, poderíamos agilizar nossa troca de informações e não perder tempo tentando acertar uma agenda onde todos pudessem se encontrar. Foram chamados também mais quatro animadores 3D e dois ilustradores para ajudar no processo de criação de concepts. E, assim, nosso filme foi sendo finalizado e o produto ficando pronto.

\subsection{Retorno com o elixir: o prêmio}

Ainda em fase de finalização para participação em festivais e disponibilização na web para download e uso dos professores, o projeto agrada a todos os que participaram de sua elaboração. Quando se encontram para comentar sobre o projeto e encaminhar a etapa de finalização, todos ainda se questionam das mesmas 
dificuldades e questionamentos de seus respectivos "mundos comuns" (escolas, estúdios, instituições de EAD). É aquela etapa da jornada do herói que todos vêem que o mundo comum continua o mesmo, mas eles de alguma forma se transformaram.

$E$, não raramente, pensam na possibilidade de começar uma "nova jornada", com novas narrativas e animações para o ensino.

\section{CONCLUSÃO}

Primeiramente, é importante ressaltar que o caminho vivenciado para a criação de uma narrativa animada, que sirva como material a ser utilizado pelo professor em sala de aula, não invalida outros caminhos, anteriormente citados, do design instrucional, do livro didático que se mexe e do estúdio que se utiliza de fatos científicos para dar maior verossimilhança às suas narrativas fictícias, dentre outros. $O$ trabalho da criação a partir de uma equipe interdisciplinar é apenas mais um caminho, que abre uma nova gama de possibilidades que permite que a animação e a educação andem de mãos dadas. Não pode ser vista como "o" caminho, mas sim "um" caminho.

Segundo ponto: é necessário que os professores e animadores estejam realmente interessados em criar narrativas que possam ser utilizadas em sala de aula. O interesse é um elemento que ajuda os envolvidos a reconhecerem suas limitações e que, diante dessas, passem a recorrer às devidas habilidades do outro para que o produto resultante desse trabalho atinja seus objetivos. Este é o elemento que permite que o trabalho seja realmente interdisciplinar.

Ainda nessa questão da interdisciplinaridade, pudemos ver que ela não acontece apenas com profissionais do Design (Animação) e profissionais da Educação, mas sim entre as ramificações que existem também dentro das respectivas áreas. Por exemplo, o fato do curta ser dirigido por um animador 2D, não impediu que o curta fosse feito em 3D. Existiu aí uma relação de confiança entre o diretor e os animadores. Reconhecendo suas limitações, o diretor não impediu uma mudança na técnica inicialmente selecionada para o filme, confiou e constatou que a novidade trazida pelos animadores 3D realmente tornaria a dinâmica do filme mais interessante.

Da mesma forma, o professor de Geografia e a professora de Química, que apesar de atuarem na grande área de Educação desenvolveram-se em subáreas distintas do conhecimento, conseguiram criar, juntamente com uma equipe de roteiristas que ajudaram a não transformar o curta em aula, uma trama com conteúdos não somente de suas subáreas, mas também de outras como Física, Biologia e Cidadania. Houve inclusive uma preocupação, por parte deles, de recorrer em alguns momentos, a professores das respectivas subáreas e até mesmo a um Biólogo, estudante de Design, que participou dos concept arts e deu consultoria aos demais modeladores 3D sobre a natureza e constituição dos animais, a fim de que suas representações guardassem uma relação direta com suas características reais.

Por fim, vale a pena pensar nas novas tecnologias disponíveis para o desenvolvimento e publicação destes trabalhos, tanto quanto refletir sobre como uma produtora de animação poderia criar diferentes projetos e distribuí-los tirando partido das facilidades oferecidas pela tecnologias. 
Sem dúvida, um dos caminhos que vale considerar é a disponibilização do material como uma websérie animada - e, para tornar possível criá-la, poderíamos pensar no sistema de crowdfunding. ${ }^{6}$

O sistema tem sido bastante utilizado pela Internet e tem ajudado pessoas de diversas áreas a deslancharem seus projetos. Hoje vemos projetos de livros, histórias em quadrinhos, bandas, cinema e animação, tanto de iniciantes quanto de veteranos, se apropriando desse sistema para viabilizar seus projetos.

Desta forma, ao disponibilizar na Internet um episódio piloto de um possível projeto de websérie animada educativa, e pedir a colaboração de pessoas para produzir próximos episódios em troca de brindes personalizados ou o crédito de apoiador na ficha técnica da animação, se apresenta como uma possibilidade de tornar sustentável uma produtora interdisciplinar de conteúdo animado para web.

Essa é apenas uma sugestão de caminho para novas produtoras que queiram se dedicar a projetos de narrativas animadas. Por outro lado, nada impede que instituições de $\mathrm{EaD}$ e produtoras já estabelecidas também passem a adotar o caminho de equipes interdisciplinares e criação coletiva no desenvolvimento de seus produtos didáticos e de entretenimento. Equipes interdisciplinares, dispostas a criar novas produções animadas e divertidas podem surgir dentro das empresas. O importante é imaginar que o objetivo principal é dar ao aluno mais uma chance de ter despertado em si o interesse pelas coisas que são ensinadas na escola, e deixar que ele pegue em sua mochila e descubra que todas as coisas que foram colocadas nela revelam um universo fascinante e maravilhoso.

\section{REFERÊNCIAS}

AUSUBEL, David P. Educational Psychology: A Cognitive View, Estados Unidos, Holt McDougal, 1978

CAMPBELL, Joseph. O herói de mil faces. São Paulo. Pensamento, 2007

COUTO, Rita Maria de Souza, OLIVEIRA, Alfredo Jefferson de. Formas do design: por uma metodologia interdisciplinar - Rio de Janeiro: 2AB: PUC-Rio, 1999

CRUZ, Gabriel. Desenvolvendo narrativas animadas para a Educação.2013. 105 f. Dissertação (mestrado) - Pontifícia Universidade Católica do Rio de Janeiro, Programa de pós-graduação em Design.

SURRELL, Jason. $\mathbf{O}$ segredo dos roteiros da Disney: dicas e técnicas para levar magia a todos os seus textos. São Paulo. Panda Books, 2009.

VOGLER, Cristopher. A Jornada do Escritor . estruturas míticas para escritores. Rio de Janeiro. Nova Fronteira, 2006

\footnotetext{
${ }^{6}$ Traduzido como financiamento coletivo: obtenção de capital para iniciativas de interesse coletivo através da agregação de múltiplas fontes de financiamento, em geral pessoas físicas interessadas na iniciativa.
} 